\title{
Orman Bölge Müdürlüğü Çalışanlarının İş Sağlığı ve Güvenliği Bilgi Düzeylerinin Belirlenmesi
}

\author{
Determination of Business Health and Safety Knowledge Levels of \\ Forest Directorate Workers
}

Serden BAŞAK, Elif IŞIK, Yalçın KANBAY

\begin{abstract}
ÖZET
Türkiye'nin \%27,2'sini kaplayan ormanlar önemli bir istihdam alanı oluşturmaktadır. Ormanlar, tehlike sınıflandırılması bakımından çok tehlikeli sınıftan az tehlikeli sınıfa kadar her alandan çalışanın bulunduğu bir çalışma alanıdır. Bu çalışmada Orman Bölge Müdürlüğü’nde çalışan personelin iş sağlığı ve güvenliği bilgi düzeylerinin belirlenmesi amaçlanmıştır. Sonuçlara göre genel İş Sağlı̆̆ ve Güvenliği Eğitimi alanların oranı \% 96,6'dır.Yaptıkları işe özel eğitim alanların oranı ise \%73,1'dir. Ancak Kişisel Koruyucu Donanım (KKD) kullananların oranı belirgin şekilde daha düşüktür $(\% 53,4)$. Bu sonuçlar, çalışan sınıflandırılması yapılmadan tüm çalışanları kapsayacak şekilde gerçekleștirilmiştir.
\end{abstract}

Anahtar Kelimeler: Orman Çalışanları, İş Sağlığı ve Güvenliği, Anket, Kişisel Koruyucu Donanım

\section{ABSTRACT}

Forests covering $27.2 \%$ of Turkey is an important area of employment. Forests are a workplace where workers from every area are involved, from very dangerous class to less dangerous class in terms of hazard classification. In this study, it was aimed to determine occupational health and safety knowledge levels of the personnel working in the Forestry Regional Directorate. According to the results, the ratio of General Occupational Health (OHS) and Safety Education is $96.6 \%$.The ratio of the special OHS education is $73.1 \%$.However, the percentage of those using Personal Protective Equipment (PPE) was significantly lower (53.4\%).These results have been made to cover all employees without employee classification.

Keywords: Forest Workers, Occupational Health and Safety, Survey, Personal Protective Equipment

Dr. Öğr. Üyesi Serden BAŞAK - Artvin Çoruh Üniversitesi, Sağlık Bilimleri Fakültesi, İş Sağlığı ve Güvenliği Bölümü, Artvin, Türkiye Asst. Prof. Serden BASAK - Artvin Coruh University, Faculty of Health Sciences, Occupational Health and Safety Department, Artvin, Turkey serdenbasak@artvin.edu.tr

Öğr. Gör. Elif IŞıK (Sorumlu Yazar) - Artvin Çoruh Üniversitesi, Sağlık Bilimleri Fakültesi, Hemşirelik Bölümü, Artvin/Türkiye Lect. Elif ISIK (Corresponding Author) - Artvin Coruh University, Faculty of Health Sciences, Nursing Department, Artvin, Turkey elifsyo@gmail.com

Dr. Öğr. Üyesi Yalçın KANBAY - Artvin Çoruh Üniversitesi, Sağlık Bilimleri Fakültesi, Hemşirelik Bölümü, Artvin/Türkiye Asst. Prof. Yalcin KANBAY - Artvin Coruh University, Faculty of Health Sciences, Nursing Department, Artvin, Turkey yalcinkanbay@hotmail.com

Bu çalışma 8-10 Nisan 2017 tarihinde 1. Uluslararası Mesleki ve Teknik Bilimler Kongresi'nde (UMTEB) Batum/Gürcistan, sözlü bildiri olarak sunulmuştur. 
a değiștirmektedir.

\section{GİRIŞ}

Ülkemizin yüzölçümünün \%27.2'sini kaplayan ormanlar bir çok biyolojik çeşitliliği içinde barındırdığı gibi önemli bir istihdam sahası da oluşturmaktadır. Ormanlar hem doğal çevrenin korunmasında hem de endüstri alanında büyük katkıları olan, ülke ekonomisinde önemli yer tutan bir alandır. Orman sadece içinde bulundurduğu biyoçeşitlilikle değil çalışanları ile de çok büyük bir fabrika gibidir. Ormanlardan sadece odun elde edilmemekte; reçine, aromatik bitkiler, meyveler, çaylar vb. maddeler elde edilmekte ve odun sanayinde, kağıt sanayinde, ilaç ve gıda endüstrisi gibi bir çok alanda da kullanılmaktadır [1].

Ormanlar, çalışan kişiler açısından da çeşitli iş alanları oluşturur, farklı iş kollarına ev sahipliği yapar. Tehlike sınıflandırılması bakımından da çok tehlikeli sınıftan az tehlikeli sınıfa kadar her alandan çalışanın bulunduğu bir çalışma alanıdır [2]. Bu durum çalışanların bütün risk faktörleri açısından değerlendirilmesi gerektirmektedir.

Orman sektörü çalışanları birçok sorunla karşı karşıyadır. Bunların başında yasal düzenlemelerdeki eksiklikler, sosyal güvenlik, ücret, çalışma koşulları, mevsimlik çalışma vb. sorunlar gelmektedir. Ormanda yapılan işler; işin zorluğu, yüksek kaza oranı, açık havada çalışma, arazide konaklama gereksinimi, iş saatlerinin ve iş süresinin değişken oluşu, iş devamlılığının olmaması, sosyal ve ekonomik açıdan yetersizlikler gibi nedenlerle diğer iş kollarından ayrı bir yapı gösterir [3]. Çalışanların iş kazası geçirmeleri veya meslek hastalıklarına yakalanmaları sorunların en büyügünü oluşturmaktadır. Ormancılık sektörü işleri çeşitli motorlu araçların kullanımından, el aletlerinin kullanımına, kas gücü gerektiren işlere kadar çalışanı farklı yönlerden etkileyen bir alandır [4]. Bu durum farklı alanlarda çalışan ama aynı ortamda bulunan insanların işle ilgili ihtiyaçlarını
Ormanda etkili ve güvenli bir şekilde çalışma için gereksiz zorlanmalardan nasıl kaçınılacağı iyi bilinmelidir. Amaç iş̧̧inin sağlığını, güvenliğini korumak, üretkenliğini ve verimliliğini artırmaktır. İş yerindeki tehlikelerden ve sağlığa zarar verebilecek etmenlerden korunmayı ve iyi bir çalışma ortamı oluşturmayı amaçlayan iş güvenliği orman sektöründe ayrı bir öneme sahiptir. ILO (Uluslararası Çalışma Örgütü) her yıl, iki orman çalışanından birinin iş kazası geçirdiği, buna karşılık diğer endüstrilerde ortalama olarak her on çalışandan birinin kaza yaptığını göstermektedir. Ülkemizde de Kastamonu Orman Bölge Müdürlüğü sınıları içerisinde 2004 -2006 döneminde odun üretiminde 18 ölümlü kaza meydana gelmiştir. Kastamonu Orman Bölge Müdürlüğü'nde üretilen 1 milyon $\mathrm{m}^{3}$ odun başına 6,9 ölüm ortaya çıkmıştır. Sertifikasyon sürecinde (20112012) ise bu değer 4 'ün altına inmiştir. Bu değer Slovenya'da 5, İsviçre'de 2, Avusturya'da 1,87 iken Almanya'da 0,67 'dir [5].

Orman İşlerinde çalışanların sağlığını korumak güvenli çalışma ortamı oluşturabilmek için çalışanları tanımak, ihtiyaçlarını belirlemek gerekmektedir. Bu çalışma Türkiye'de bir Orman Bölge Müdürlüğü’ne bağlı bulunan çalışanlar üzerinde, onların işs sağlığı ve güvenliği bilgi düzeylerini belirlemek amacıyla yapılmıştır.

\section{YÖNTEM}

\section{A. Araştırmanın Tipi}

$\mathrm{Bu}$ araştırma bir Orman Bölge Müdürlüğü’nde çalışan personelin iş sağlığı ve güvenliği bilgi düzeylerini belirlemek amacıyla Tanımlayıcı tipte yapılmış bir çalışmadır.

\section{B. Araştırmanın Yapıldığı Yer}

Bu çalışma 2016 yılının Ocak-Mart ayları arasında bir 
Tablo 1: Bazı Bireysel Özelliklere Ait Ortalamalar

\begin{tabular}{|c|c|c|c|c|c|}
\hline Değişken & $\mathrm{n}$ & minimum & maksimum & ortalama & St hata \\
\hline Yaş & & 25 & 66 & 47,93 & 0,441 \\
\hline Günlük çalışma saati & & 5 & 12 & 8,12 & 0,056 \\
\hline Haftalık çalışma saati & 208 & 25 & 85 & 44,54 & 0,455 \\
\hline Çalışma yılı & & 1 & 38 & 22,15 & 0,451 \\
\hline Aynı işi yapma yılı & & 1 & 35 & 15,07 & 0,581 \\
\hline
\end{tabular}

Orman Bölge Müdürlüğüne bağlı işletme şefliklerinde yapılmıştır.

\section{Evren ve Örneklem}

Araştırmanın evrenini, orman bölge müdürlügünde 2016 yılında kadrolu çalışan 749 çalışan oluşturmaktadır. Örneklem seçimde, evren sayısı bilinen örneklemlerde örneklem seçme formülü kullanılarak $\% 5$ hata payı ile $\% 90$ güvenilirlik sağlanmış ve toplam 208 çalışanda araştırma yapılmıştır.

\section{Veri Toplama Araçları}

Veri toplama araçları olarak literatür taranarak araştırmacılar tarafından hazırlanan "Sosyodemografik Özellikler Formu” ve bu çalışmaya özel hazırlanan "İş Sağlığı ve Güvenliği Anketi” tüm katılımcılara uygulanmıştır.

\section{E. Verilerin Değerlendirilmesi}

Verilerin değerlendirilmesi SPSS 17.0 ortamında; sayı, yüzde, ortalama kullanılarak yapılmıştır.

\section{F. Araştırmanın Etik Yönü}

Çalışmanın yapılabilmesi için Artvin Çoruh Üniversitesi Etik Kurulu Onayı (06.01.2016, 2016/1 - Karar No:10) ve çalışmanın yapıldığı Orman Bölge Müdürlüğü’nden çalışma izni ile katılımcılardan bilgilendirilmiş onam alınmıştır.

\section{BULGULAR}

$\mathrm{Bu}$ araştırmaya toplam 208 kişi katılmıştır. Uygulanan "Sosyodemografik Özellikler Formu" sonuçlarına göre; çalışmaya katılanların yaş ortalaması 47,93; günlük ortalama çalışma saati 8,12 ; Haftalık çalışma saati ortalaması 44,54; çalışma yılı ortalaması 22,15; aynı işi yapma sürelerinin ortalamaları 15,07 yıldır (Tablo 1).

Çalışmaya katılanların \%90,4’ü erkek, \%9,6'sı kadındır. Çalışmaya katılanların büyük bir bölümü $(\% 39,9)$ ilkokul mezunudur. \%26,9'u ortaokul ve lise mezunu, \% 6,3'üu üniversite mezunudur. Katılımcıların \%70,2'si işçi; \%9,6's1 şoför, \% 9,1'1 memur, \%6,7'si operatör, \%4,3'ü diğer alanlarda çalışmaktadır (Tablo 2).

Tablo 2: Bazı Değişkenlerin Frekansları

\begin{tabular}{cccc}
\hline \multirow{2}{*}{ Cinsiyet } & Değişken & $\mathrm{n}$ & $\%$ \\
\cline { 2 - 4 } & Krkek & 188 & 90,4 \\
\hline \multirow{3}{*}{ Eğitim } & Illkokul & 83 & 9,6 \\
\cline { 2 - 4 } & Ortaokul & 56 & 39,9 \\
\cline { 2 - 4 } & Lise & 56 & 26,9 \\
\cline { 2 - 4 } & Üniversite & 13 & 26,9 \\
\cline { 2 - 4 } & İşçi & 146 & 6,3 \\
\hline \multirow{2}{*}{ Meslek } & Şoför & 20 & 70,2 \\
\cline { 2 - 4 } & Memur & 19 & 9,6 \\
\cline { 2 - 4 } & Operatör & 4 & 9,1 \\
\cline { 2 - 4 } & Diğer & 9 & 6,7 \\
\hline
\end{tabular}


Tablo 3: Değişkenlere Göre Frekanslar

\begin{tabular}{|c|c|c|c|c|c|c|}
\hline & \multicolumn{2}{|c|}{ EVET } & \multicolumn{2}{|c|}{ HAYIR } & \multicolumn{2}{|c|}{ FIKRIM YOK } \\
\hline & $\mathrm{n}$ & $\%$ & $\mathrm{n}$ & $\%$ & $\mathrm{n}$ & $\%$ \\
\hline Genel İş Sağlığı ve Güvenliği (iSG) eğitimi aldınız mı? & 201 & 96,6 & 6 & 2,9 & 1 & 0,5 \\
\hline Yapttğınız işe özel isG eğitimi aldınız mı? & 152 & 73,1 & 55 & 26,4 & 1 & 0,5 \\
\hline Eğitiminiz belli aralıklarla tekrarlanıyor mu? & 137 & 65,9 & 67 & 32,2 & 4 & 1,9 \\
\hline Hiç iş kazası yaşadınız mı? & 22 & 10,6 & 184 & 88,5 & 2 & 1,0 \\
\hline Herhangi bir meslek hastalığınız var mı? & 22 & 10,6 & 182 & 87,5 & 4 & 1,9 \\
\hline Yaptğınız işin tehlikeli olduğunu düşünüyor musunuz? & 95 & 47,5 & 113 & 54,3 & 0 & 0 \\
\hline İmkanınız olsa başka bir iş yapmak ister misiniz? & 102 & 49,0 & 103 & 49,5 & 3 & 1,4 \\
\hline Sizce bu görevi daha güvenli yapmak mümkün mü? & 138 & 66,3 & 61 & 29,3 & 9 & 4,3 \\
\hline İş yerinde sağılık ve güvenlik ile ilgili çalışan temsilciniz var mı? & 146 & 70,2 & 54 & 26,0 & 8 & 3,8 \\
\hline İşe girmeden önce sağlık kontrolünden geçtiniz mi? & 198 & 95,2 & 10 & 4,8 & 0 & 0 \\
\hline İş yerinde periyodik sağlık muayeneleriniz yapılıyor mu? & 145 & 69,7 & 60 & 28,8 & 3 & 1,4 \\
\hline İşiniz için herhangi bir aşı oldunuz mu? & 59 & 28,4 & 148 & 71,2 & 1 & 0,5 \\
\hline $\begin{array}{l}\text { İş yeriniz iş sağ|ığı ve güvenliği, hijyen, kişisel ve ortak koruyucu } \\
\text { donanım konularında tavsiyede bulunuyor mu? }\end{array}$ & 154 & 74,1 & 50 & 24,0 & 4 & 1,9 \\
\hline $\begin{array}{l}\text { İş yeriniz iş sağlığı ve güvenliği önlemlerine uyulup uyulmadığını } \\
\text { kontrol ediyor mu? }\end{array}$ & 160 & 76,9 & 41 & 19,7 & 7 & 3,4 \\
\hline Kişisel Koruyucu Donanım (KKD) kullanıyor musunuz? & 111 & 53,4 & 93 & 44,7 & 4 & 1,9 \\
\hline Yapttğınız işe uygun KKD verildi mi? & 116 & 55,8 & 86 & 41,3 & 6 & 2,9 \\
\hline $\begin{array}{l}\text { Yapttğınız işe uygun KKD verilmesi gerektiğine inanıyor musu- } \\
\text { nuz? }\end{array}$ & 132 & 63,5 & 63 & 30,3 & 13 & 6,3 \\
\hline $\begin{array}{l}\text { Sizce iş yeriniz sağlık ve güvenliğin korunması için gerekli ön- } \\
\text { lemleri almada yeniliklere uyum sağlıyor mu? }\end{array}$ & 165 & 79,3 & 35 & 16,8 & 8 & 3,8 \\
\hline $\begin{array}{l}\text { İşyeriniz, yaptğınız işin ihtiva ettiği sağlık tehlikeleri ve diğer } \\
\text { riskler hakkında sizi yeterince bilgilendiriyor mu? }\end{array}$ & 152 & 73,1 & 47 & 22,6 & 9 & 4,3 \\
\hline $\begin{array}{l}\text { İşyeri yönetiminiz işyerinde sağlıklı ve güvenli çalışma ortamının } \\
\text { sağlanması için gerekli önlemleri alıyor mu? }\end{array}$ & 167 & 80,3 & 35 & 16,8 & 6 & 2,9 \\
\hline Arkadaşlarınızla iş sırasında hiç şakalaşıyor musunuz? & 89 & 42,8 & 119 & 57,2 & 0 & 0 \\
\hline $\begin{array}{l}\text { Çalıştğınız alanla ilgili yeterli bilgiye sahip olduğunuzu düşünü- } \\
\text { yor musunuz? }\end{array}$ & 182 & 87,5 & 25 & 12,0 & 1 & 0,5 \\
\hline İlk yardım konusunda eğitim aldınız mı? & 173 & 83,2 & 35 & 16,8 & 0 & 0 \\
\hline İlk yardım konusunda eğitim aldırıldığını biliyor musunuz? & 179 & 86,1 & 25 & 12,0 & 4 & 1,9 \\
\hline İlk yardım eğitimi almış iş arkadaşlarınızı tanıyor musunuz? & 173 & 83,2 & 31 & 14,9 & 4 & 1,9 \\
\hline İsyerinizle ilgili herhangi bir rahatsızlık duyuyor musunuz? & 54 & 26,0 & 150 & 72,1 & 4 & 1,9 \\
\hline
\end{tabular}

Bu çalışma için özel olarak oluşturulmuş ve katılımcıla- ları Tablo 3 'te verilmiştir. ra uygulanmış olan “İş Sağlı̆̆ı ve Güvenliği Anketi” sonuç- 


\section{TARTIŞMA}

Çalışmaya katılanların yaş ortalamaları 25 ile 66 arasında değişse de ortalama 47,93'tür. Araştırmaya katılanların yaş ortalaması ülkemizdeki orman işçilerinin çalışma yaşı ile paraleldir. Yaş grubu olarak çalışma yaşı ortalaması özellikle ülkemizdeki orman işçilerinin çalışma yaşlarına benzerdir. Yapılan çalışmalar da genellikle yaş ortalaması 37 ile 45 arasında değişmektedir $[3,6,7]$.

Araştırmaya katılanların; günlük ortalama çalışma saati 8,12, haftalık çalışma saati ortalaması 44,54 saattir. 4857 sayılı İş Kanunu'nun 63. maddesi, haftalık çalışma süresinin 45 saat olduğu, aksi kararlaştırılmadıkça bu sürenin çalışma günlerine eşit olarak dağıtılacağını hükme bağlamaktadır [8]. Dolayısı ile işçiler kanuna uygun olarak çalıştırılmaktadırlar. Çalışanların çalışma yılı ortalaması 22,15 ve aynı işi yapma sürelerinin ortalamaları 15,07 yıldır. Benzer çalışmalarda da çalışanların çoğunluğunun ortalama 20 ve üzeri yıl çalıştıkları [9], orman işçilerindeki başka bir çalışmada da 20 yılın üzerine çıkıldığında çalışan sayısının azaldığı görülmektedir [3]. Bunun nedeni işin fazla güç gerektirmesi ve işin zorluğu gibi nedenler olabilir. Aynı zamanda 15 yaş gibi küçük çalışma yaşında işe başlanması 20 yıl üstü çalışmayı engellemektedir. Çalışanların aynı işte uzun süre çalışmaları, yaptıkları işlerde tecrübeli olduklarını göstermektedir. Fakat uzun süre aynı işte çalışmak her ne kadar tehlikeleri önceden görmeyi sağlasa da tecrübeye dayanarak tehlikenin önemsenmemesine, kanıksamaya ve dolayısı ile iş kazası riskinin oluşmasına sebep olabilmekte$\operatorname{dir}[10$, p. 198].

Çalışmaya katılanların \%90,4’ü erkek, \%9,6'sı kadındır. Orman işleri genellikle daha çok kas gücü gerektiren işler olduğundan çalışanların çoğunluğunun erkek olması doğaldır. Kadın katılımcılar sadece ofis ortamında çalışmaktadır. Ormancılık işleri ile ilgili yapılan çalışmaların çoğunluğunda erkekler ile çalışılmıştır [11].

Çalışmaya katılan çalışanların eğitim durumu incelendiğinde lise altı eğitim seviyesi \%66,8 olarak belirlenmiştir. Orman işlerine yönelik yapılan diğer çalışmalarda da katılımcıların eğitim seviyeleri bu çalışmanın verilerine benzerdir [7]. Özellikle iş kazalarının çok olduğu meslekler içerisinde yer alan orman işleri, çalışanların öğrenim durumları bakımından da lise altı öğrenim (\% 66,8) durumuyla daha çok dikkat çekmektedir (Tablo 2). İş kazası geçirme oranı eğitimle yakın ilişkilidir. Lise altı öğrenim durumlarında iş kazaları yüksektir [12]. Çalışanların öğrenim seviyelerinin düşük olması hem ekonomik hem de iş kazası bakımından orman sektöründe önemli bir yer tutar [5].

Çalışmaya katılanlar meslekleri incelendiğinde, \% 70,2'si işçi; \%9,6'sı şoför, \% 9,1'ı memur, \%6,7'si operatör, \%4,3’ü diğer alanlarda çalışmaktadır.

Çalışmaya katılanların \%96,6'sı gibi çok büyük bir oranının iş sağlığı ve güvenliği (ISG) eğitimi aldıkları tespit edilmiştir. Mesleki İSG eğitimleri yine yüksek bir oran olan \%73,1'dir. İSG eğitimlerinin verilmesinde ve önlemlerin alınmasında iş verenlerin eğitim verme ve bilgilendirme yükümlüğü vardır [13]. Ayrıca işçilerin işverenle birlikte hareket etmesi olayı benimsemeleri oldukça önemlidir [12]. Bu araştırma sonuçları ISG konusunda kurumun titizlikle çalıştığını, çalışanlarını eğittiği, özellikle mesleki İSG konusunda eğitimlerinin yüksek oranda verildiğini göstermektedir. Teknik elemanlarla yapılan başka bir çalışmada İSG eğitimimin \%50 civarında olduğu görülmüştür [9].

Ormancılık işleri, İş Sağlığı ve Güvenliğine İlişkin İşyeri Tehlike Sınıfları Tebliği'nde tehlikeli ve çok tehlikeli sınıflarda yer almıştır [2]. Bu durum çalışanlar İSG eğitimlerinin önemini özellikle vurgulamaktadır.

İş kazası yaşayanların oranı ise \%22'dir. Ancak genelde 


\section{2}

çalışanlar için "İş Kazası" daha çok iş görmemezlikle sonuçlanan ciddi kaza ve yaralanmalar olarak düşünülmektedir. Yapılan başka bir çalışmada orman işçilerinde iş kazası görülme oranı bir yıl içerisinde yaklaşık üç işçiden birinin iş kazası geçirdiği şeklinde belirtilmiştir [7]. Ayrıca \% 42,8 'lik bir oranda katılımcının çalışma ortamında birbirleri ile şakalaştığı tespit edilmiştir. İş yerinde yapılan bu şakalarda iş kazalarına davetiye çıkaran önemli unsurlardan biridir.

İş sağlığı ve güvenliği eğitimlerinin periyodik tekrarı ve periyodik muayenelerle ilgili cevaplara bakıldığında, rakamların belirgin oranlarda düştüğü görülmektedir (\% 65,9). Bu, çalışanların alınan bir eğitimin yeterli olduğunu düşünmeleri ve periyodik eğitimleri önemsememeleri veya periyodik eğitimlerin önemini bilmemeleri ile açıklanabilir.

İlk yardım eğitimi alanların oranı oldukça yüksektir (\% 83,2). İlk yardım, İlk Yardım Yönetmeliği (2015) gereği, İSG kapsamında "tehlikeli işyerlerinde çalışanlarda her 15 çalışana kadar bir ilk yardımcı, çok tehlikeli işyerlerinde çalışanlarda her 10 çalışana kadar bir ilk yardımcı bulundurma” zorunluluğu getirilmiştir [14]. Ayrıca işveren, 6331 sayılı İSG kanunu gereği "İşyerinde ilkyardımla ilgili düzenlemeleri yapmak" konusunda sorumlu tutulmuştur. İşveren işyerinde çalışanların yaralanması veya hastalanması halinde ilk yardım hizmetinin uygun koşullarda ve yeterli düzeyde verilmesini sağlayacak ekipman ve personele sahip olduğunu garantilemelidir” [15]. Yapılan bu çalışmada, kurumun ilk yardım konusuna verdiği önem ve yasalara uygunluğunu da açıkça görülmektedir. İş kazası ve yaralanmaların çok sık karşılaşılabileceği bir sektör olması nedeniyle orman işlerinde ilk yardım ayrı bir öneme sahiptir.

Yapılan iş göz önüne alındığında Kişisel Koruyucu Donanımın (KKD) kullanımı ayrı bir öneme sahip olmaktadır. Ancak buna rağmen araştırma sonuçlara göre çalışanla- rın yaklaşık yarısı $(\% 53,4)$ KKD kullanmaktadır. Bunun bir nedeni, çalışmanın sadece ormanda çalışan işçilere değil, ilgili Orman Bölge Müdürlüğü’nde çalışan tüm memur ve büro çalışanı gibi diğer personele de uygulanmış olmasıdır. Başka bir nedeni ise KKD kullanımının öneminin yeterince bilinmemesinden veya KKD kullanarak işlerini daha verimli yapamadıklarını düşünmelerinden dolayı olabilir. İş Sağlığı ve Yönetmeliği' ne göre, KKD ve iş elbiseleri işin özelliğine göre kullanılmalı bununla ilgili gerekli uyarılar yapılmalıdır. İşveren bunları yapmakla, işçi de bunları uygulamakla yükümlüdür [14].

Katılımcıların \%95,2'si işe girmeden önce sağlık kontrolünden geçmiş olduklarını beyan etmişlerdir. \% 69,72'sinin ise periyodik sağlık muayeneleri yapılmıştır. Kanun gereği, tehlikeli ve ağır işlerde çalışacakların rutin muayene ve periyodik muayenelerinin yapılması şarttır [14].

\section{SONUÇ}

Sonuç olarak, Türkiye'de bir Orman Bölge Müdürlügü̈'nde memurdan orman işçisine, saha çalışanından ofis çalışanına kadar tüm çalışanların bu çalışma için özel olarak hazırlanmış anketi yanıtladığı bir çalışma yürütülmüştür. Çalışmanın yapıldığı Müdürlükte katılımcıların İSG konusunda yeteri kadar bilgi sahibi oldukları, İSG uygulamalarının kanuna uygun şekilde yapıldığı görülmektedir. Ancak çok ciddi sonuçlara yol açabilecek iş yerinde şakalaşma hususunda çalışanlar ayrıca uyarılmalı ve bilgilendirilmelidir. Eğitimlerin periyodik tekrarı ve KKD kullanımı konuları ise başka önemli hususlardır.

Yapılacak sonraki çalışmaların Bölge Müdürlüğü içindeki meslek gruplarına özel olması (ofis çalışanları, operatörler, işçiler vb.) ve anket sorularının o meslek grubuna özel olarak hazırlanması, varsa spesifik sorunların tanımlan- 
ması değerlendirilme için daha uygun olacağı ön görülmektedir.

\section{KAYNAKLAR}

[1] Ormancilık Özel İhtisas Komisyon Raporu, “9. Kalkınma Planı”, T.C. Başbakanlık Devlet Planlama Teşkilatı. Yayın no:2712, Ankara, 2007.

[2] İş Sağlığı ve Güvenliğine İlişkin İşyeri Tehlike Sınıfları Tebliğinde Değişiklik Yapılmasına Dair Tebliğ, T.C. Resmi Gazete, 28602, 2013.

[3] Acar H.H. \& Şentürk N., "Artvin Yöresindeki Orman İşçilerinde İşçi Sağlığı Üzerine Bir Araştırma," Ístanbul Üniversitesi Orman Fakültesi Dergisi, 49(1), 25-38, 1999.

[4] Enez K., "Ormancılıkta Üretim İşçiliğinde Antropometrik Verilerin ve Çalışma Duruşlarının Kaza Risk Faktörü Olarak Değerlendirilmesi," Yayımlamamış Doktora Tezi, Karadeniz Teknik Üniversitesi Fen Bilimleri Enstitüsü Orman Mühendisliği Anabilim Dalı, Trabzon, 2008.

[5] Ergün M.O., "Orman Üretiminde Çalışanların Eğitimi,Ağaç Kesme ve Boylama Operatörü,” T.C. Orman ve Su İşleri Bakanlığı Orman Genel Müdürlüğü, Ankara, 2014.

[6] Gedik T., Akyüz K.C. \& Batu C., "Orman Endüstri İşletmelerinde Yönetici İş Tatmin Düzeyinin Belirlenmesi (Düzce İli Örneği)," Kastamonu Üni., Orman Fakültesi Dergisi, 1, 1-11, 2009.

[7] Enez K., Topbaş M. \& Acar H.H., "An evaluation of the occupational accidents among logging workers within the boundaries of Trabzon Forestry Directorate, Turkey," International Journal of Industrial Ergonomics, 44, 621-628, 2014.

[8] İş Kanunu, T.C. Resmi Gazete, 25134, 2003.

[9] Güvencin Ö. \& Aybek A., "Teknik Personelin İş Güvenliği Konusundaki Eğitim Düzeyleri Üzerine Bir Araştırma,” Teknoloji, 6(1-2), 69-77, 2003.

[10] Okur Z. \& Öztaş S., "İş Kazaları ve Korunma," F. Tanır içinde, Temel İş Sağlığı ve Güvenliği Eğitimi, Ankara, Akademisyen Kitabevi, 2016.

[11] Yılmaz R., Artvin Yöresinde Ormancılık İşlerinde Çalışan işçilerin Fiziksel İş Yüklerinin Belirlenmesi, Yayımlanmamış Yüksek Lisans Tezi, Artvin Çoruh üniversitesi Fen Bilimleri Enstitüsü Orman Mühendisliği Anabilim Dalı, Artvin, 2012.

[12] Tunay M. \& Emir T., "Ormancilık üretim işlerinde iş sağlığı ve güvenliğinin yasal çerçevede değerlendirilmesi," Türkiye Ormancılık Dergisi, 16(2), 195-202, 2015.

[13] Kılkış İ., "İşverenin İş Sağllğı ve Güvenliği Eğitimi Verme Yükümlülüğü Üzerine Bir İnceleme," Çalışma İlişkileri Dergisi, 3(1), 23-47, 2012.

[14] İlkyardım Yönetmeliği, T.C. Resmi Gazete, 29429, 2015.

[15] İş Sağlığı ve Güvenliği Kanunu, T.C. Resmi Gazete, 28339, 2012.

Teşekkür: Çalışmanın yapılmasında bize her türlü desteği sağlayan ilgili Orman Bölge Müdürlüğ̈̈ne, Sayın Makine Mühendisi Kemal Çetiner'e ve Elektrik Mühendisi Sertaç Işık'a teşekkür ederiz. 
